\title{
¿LAS EXCLUSIONES DEL CONTRATO DE SEGURO DEBEN TENER RELACIÓN CAUSAL CON EL SINIESTRO? NUEVAS PERSPECTIVAS DESDE LA CORTE SUPREMA DE JUSTICIA*
}

\section{MUST EXCLUSIONS IN INSURANCE BE CAUSALLY LINKED TO THE LOSS? NEW PERSPECTIVES FROM THE SUPREME COURT OF JUSTICE}

\author{
MARÍA LUISA TRUJILLO GÓMEZ ${ }^{* *}$ \\ DANIEL OSSA GÓMEZ ${ }^{* * *}$ \\ Fecha de recepción: 26 de octubre de 2021 \\ Fecha de aceptación: 15 de noviembre de 2021 \\ Disponible en línea: 30 de diciembre de 2021 \\ Para citar este artículo/To cite this article
}

Trujillo Gómez, María Luisa \& Ossa Gómez, Daniel. ¿Las exclusiones del contrato de seguro deben tener relación causal con el siniestro? Nuevas perspectivas desde la corte suprema de justicia, 55 Rev.Ibero-Latinoam.Seguros, 121-142 (2021). https://doi.org/10.11144/ Javeriana.ris55.ecsr

doi:10.11144/Javeriana.ris55.ecsr

\footnotetext{
* Artículo producto del estudio del caso que falló la Corte Suprema de Justicia el 23 de noviembre del año 2020 (SC4527-2020), con ponencia del Magistrado Francisco Ternera Barrios, en el proceso con radicado 11001-31-03-019-2011-00361-01.

** Candidata a Magíster en Derecho Administrativo de la Universidad Autónoma Latinoamericana (UNAULA). Abogada de la Universidad EAFIT. Monitora académica de la materia Personas Jurídicas del Derecho Privado de la Universidad EAFIT. Monitora académica de la materia Títulos Valores de la Universidad Autónoma Latinoamericana (UNAULA). Certificada en los cursos denominados "Bioethics: The Law, Medicine, and Ethics of Reproductive Technologies and Genetics" y "Contract Law: from Trust to Promise to Contract" de la Universidad de Harvard. Abogada de la firma Tamayo Jaramillo \& Asociados desde el año 2016. Correo electrónico: maria.trujillo@tamayoasociados.com

*** Máster en Derecho (con mérito) Newcastle University (Reino Unido), Especialista en Derecho de los Seguros de la Pontificia Universidad Javeriana, Especialista en Responsabilidad Civil y Seguros de la Universidad Pontificia Bolivariana, Abogado de la Universidad Pontificia Bolivariana. Profesor de cátedra de la Universidad Pontificia Bolivariana y de la Universidad de Medellín. Autor y par académico en revistas indexadas. Socio de la firma Tamayo Jaramillo \& Asociados fundada por el Dr. Javier Tamayo Jaramillo. Correo electrónico: daniel.ossa@tamayoasociados.com
} 


\section{RESUMEN}

El 23 de noviembre del año 2020, la Sala Civil de la Corte Suprema de Justicia falló un recurso extraordinario de casación interpuesto por una empresa transportadora ${ }^{1}$, en contra de la sentencia de segunda instancia proferida por el Tribunal Superior de Distrito Judicial de Bogotá. En dicho proceso judicial, se discutía si las exclusiones del contrato de seguro, para ser alegadas por la aseguradora, debían ser la causa adecuada del siniestro.

Con el fin de dar más contexto sobre el caso, anticipamos que la parte demandante, amparándose en la posición de un sector de la doctrina, con precursores como el maestro J. EfréN Ossa Gómez, sostuvo a lo largo del proceso que las exclusiones legales o convencionales debían aplicarse con un criterio causal para ser invocadas como eximentes de responsabilidad del asegurador.

Por su parte, la aseguradora demandada sostenía que las exclusiones no sólo podían ser aplicadas con un criterio causal sino, también, de acuerdo con otras circunstancias técnicas del contrato de seguro, así las mismas no fueran la causa adecuada del siniestro, en virtud de la posibilidad de delimitar el riesgo asegurado establecido en el artículo 1056 del Código de Comercio.

La Corte Suprema de Justicia apoyó la postura de la aseguradora y, apartándose de la posición clásica de reputados autores, adoptó un criterio novedoso al considerar que, por las amplias facultades que tiene la aseguradora para delimitar el riesgo asegurado, basta con que la exclusión tenga una explicación técnica -aunque no sea la causa adecuada del siniestro- para prosperar, siempre que la misma tenga relación con los hechos o condiciones que antecedieron la ocurrencia del siniestro.

Palabras clave: Criterio técnico, Delimitación del riesgo, Exclusión, Póliza de seguro, Relación de causalidad, Siniestro.

M.P. Francisco Ternera Barrios, ref: SC4527-2020. 


\section{ABSTRACT}

On November 23, 2020, the Civil Chamber of the Supreme Court of Justice ruled a Cassation Suit filed by a transportation company against the second instance judgment rendered by the Superior Court of Bogotá. In this case, it was disputed whether the exclusions of the insurance contract, in order to be successfully alleged by the insurer, need to be the adequate cause of the loss.

In order to provide more context on the case, we anticipate that the plaintiff, relying on the position of a sector of the doctrine, with reputed precursors such as J. Efrén Ossa Gómez, argued throughout the process that the legal or conventional exclusions must be applied with a causal criteria to be invoked as exonerating of liability of the insurer.

On the other hand, the defendant insurer argued that the exclusions could not only be applied with a causal criteria but also according to other technical circumstances of the insurance contract, even if they were not the adequate cause of the loss.

The Supreme Court of Justice supported the insurer's position and, departing from the position of some reputable authors, adopted a novel criteria by considering that, due to the broad powers of the insurer to describe the insured risk (article 1056 of the Code of Commerce), it is sufficient that the exclusion has a technical explanation -even if it is not the adequate cause of the loss- to be successful, provided that it is related to the facts or conditions that preceded the occurrence of the loss.

Keywords: Technical criteria, Insured risk, Exclusions, Insurance Policy, Causal link, Insurance Loss.

SUMARIO: INTRODUCCIÓN. 1. Antecedentes. 2. Demanda y trámite del proceso. 1.3. Las decisiones de primera y segunda instancia. 1. POSICIÓN DE LA EMPRESA TRANSPORTADORA. 2. POSICIÓN DE LA ASEGURADORA. 2.1. La aseguradora tiene la potestad de delimitar el riesgo a través de límites positivos y negativos de los eventos amparados. 2.2 La interpretación de los amparos consagrados en las pólizas de seguro debe ser realizada de manera restrictiva, limitada, consultando la voluntad de las partes plasmada en el texto del contrato. 2.3. Las exclusiones no requieren un nexo de causalidad con el siniestro para que sea aplicable la delimitación negativa del riesgo asegurable. 3. POSICIÓN DE LA CORTE SUPREMA DE JUSTICIA Y COMENTARIOS. 3.1. Interpretación del contrato de seguro celebrado entre las partes. 3.2. Validez de la exclusión del sobrecupo en este caso. 4. CONCLUSIONES. 5. BIBLIOGRAFÍA. 


\section{INTRODUCCIÓN}

\section{Antecedentes}

El 30 de mayo de 2009, en la vía que conduce del municipio de La Mesa a Bogotá, una buseta afiliada a una empresa transportadora sufrió un lamentable accidente, al rodar por un abismo de aproximadamente 42 metros, dejando múltiples fallecidos y personas gravemente lesionadas.

La empresa transportadora presentó una reclamación formal a la aseguradora en responsabilidad civil del vehículo accidentado, pretendiendo la indemnización de perjuicios de las víctimas directas e indirectas del accidente. La aseguradora decidió objetar tal reclamación, porque dentro de los documentos aportados por el asegurado se encontró que la buseta contaba, al momento del accidente, con un evidente sobrecupo. Esa circunstancia se encontraba expresamente excluida de cobertura en la delimitación negativa del riesgo descrito en el clausulado de la póliza. Sin embargo, la causa del accidente, de acuerdo con los informes policiales y periciales de reconstrucción de los hechos, había sido una falla en los frenos del vehículo asegurado.

Pese a la decisión que tomó la aseguradora de objetar la reclamación formulada, la empresa transportadora se apresuró a celebrar una serie de conciliaciones y transacciones con las víctimas del accidente de tránsito sin el consentimiento de la primera, amparándose en su deber de mitigar el daño.

\section{Demanda y trámite del proceso}

Pretendiendo el reembolso de las sumas de dinero pagadas a las víctimas, la empresa transportadora presentó, ante los Juzgados Civiles del Circuito de Bogotá, demanda ordinaria de responsabilidad civil contractual en contra de la aseguradora argumentando, entre otras cosas, que la causa adecuada del accidente fue una falla mecánica en el sistema de frenado de la buseta (evento que no estaba excluido de la póliza de seguros).

Por su parte, la aseguradora se defendió de las acusaciones de la parte demandante argumentando que las exclusiones no requieren un nexo de causalidad con el siniestro, por lo que era perfectamente plausible que la exclusión por sobrecupo, pactada en el clausulado de la póliza de seguro, prosperara aún si se determinaba que la causa adecuada del accidente fue una falla en los frenos de la buseta.

El debate probatorio del proceso culminó con la demostración de tres circunstancias fundamentales: (1.) la causa adecuada del accidente fue la falla mecánica en el sistema de frenado de la buseta, (2.) la buseta viajaba, al momento del accidente, con un evidente sobrecupo y, (3.) el sobrecupo estaba clara y expresamente excluido de cobertura en la póliza tomada por la transportadora, aunque no había sido la causa del siniestro. 


\section{Las decisiones de primera y segunda instancia}

El juzgado de primera instancia desestimó las pretensiones de la demanda argumentando que en el clausulado de la póliza de seguro se había pactado, expresamente, la exclusión del sobrecupo y, en el caso concreto, se había demostrado que la buseta tenía capacidad para transportar 28 personas, pero, al momento del accidente, viajaban -al menos- 36 pasajeros, luego de excluir del listado de ocupantes al conductor del vehículo y a los "niños de brazos". 2

Ante dicha decisión, la parte demandante apeló la sentencia y el Tribunal Superior de Bogotá confirmó la decisión argumentando, entre otras cosas, que la carga excesiva del vehículo accidentado fue una posible causa adecuada de las fallas en su funcionamiento, específicamente del sistema de frenos. De ahí que la exclusión de esta eventualidad, como riesgo en el contrato de seguro, se mostraba razonable, legal y proporcionada y, en consecuencia, la aseguradora no era la llamada a reparar el daño reclamado.

No conforme con la decisión, la parte demandante interpuso recurso extraordinario de casación ante la Corte Suprema de Justicia, en contra de la sentencia proferida por el Tribunal Superior de Bogotá, y este se resolvió el pasado 23 de noviembre del año 2020.

El objetivo de este artículo es ilustrar a la comunidad académica sobre las dos posturas que existen en torno a si las exclusiones pactadas en un contrato de seguro deben tener relación causal con el siniestro, para que puedan ser invocadas válidamente por las aseguradoras, por un lado, y sobre la postura novedosa que adoptó la Corte Suprema de Justicia el año pasado cuando resolvió el recurso extraordinario de casación presentado por la empresa transportadora, por el otro.

Para desarrollarlo, expondremos, en primer lugar, la posición que adoptó la parte demandante a lo largo del proceso (que coincide, justamente, con lo que había dicho la jurisprudencia y doctrina mayoritaria en la materia hasta la fecha); en segundo lugar, la postura que sostuvo la aseguradora para controvertir la tesis del demandante, y, en tercer lugar, el análisis que hizo la Corte Suprema de Justicia sobre ambas posturas y la conclusión a la que llegó en la sentencia de casación proferida el pasado 23 de noviembre del año 2020.

\section{POSICIÓN DE LA EMPRESA TRANSPORTADORA}

La empresa transportadora sostuvo a lo largo del debate probatorio que es un presupuesto esencial para alegar válidamente una exclusión pactada en el contrato de seguro, el hecho de que el evento expresamente excluido haya sido la causa eficiente del siniestro presentado.

\footnotetext{
${ }^{2}$ Al respecto, el parágrafo del artículo 82 del Código Nacional de Tránsito Terrestre (Ley 769 de 2002) señala que "[n]ingún vehículo podrá llevar un número de pasajeros superior a la capacidad señalada en la licencia de tránsito, con excepción de los niños de brazos". Y, a su vez, el concepto MT-1350-2 - 23801 del 29 de abril de 2008, elaborado por el Ministerio de Transporte, indicó que "se entenderá que es menor 'de brazos' todo niño y toda niña menor de 2 años.'.
} 
Esta es la postura del tratadista J. Efrén Ossa G (1991, p. 484), el cual, dentro de su explicación sobre las exclusiones, explica que “(...) Para que puedan invocarse como eximentes de responsabilidad del asegurador, deben hallarse con el siniestro en relación de causa a efecto, al punto que éste no hubiese ocurrido de no haber mediado la intervención de aquellas".

Asimismo, el exmagistrado de la Corte Suprema de Justicia Carlos Ignacio Jaramillo Jaramillo (2012, p. 189) sostiene que "el evento -o hecho-excluido debe ser-dentro de la secuencia causal la causa adecuada del daño sufrido por el asegurado. Si ello tiene lugar no se materializará en puridad el siniestro y, por ende, no surgirá la obligación de estirpe indemnizatoria a cargo del asegurador"'.

Se señaló que, precisamente, esa es la principal diferencia entre una exclusión y la violación de una garantía en el contrato de seguro. Mientras que la infracción de la garantía puede ser alegada por la aseguradora para terminar o anular el contrato, desde el mismo momento en que conoce de tal infracción y "sea o no sustancial respecto del riesgo", ${ }^{4}$ en el caso de las exclusiones, las mismas sólo pueden ser alegadas cuando existen una relación causal con el siniestro, so pena de que dicha cláusula resultase abusiva y desproporcionada.

Adicionalmente, agregó que no solo es necesaria la presencia del nexo de causalidad material y jurídica entre el siniestro y la exclusión, sino que la aseguradora debe probar los hechos, acontecimientos, fenómenos, circunstancias o, simplemente, las causas excluyentes de su responsabilidad contractual (2012, p. 189), ${ }^{5}$ y que ello no había ocurrido en el caso concreto, pues no se había demostrado la vinculación causal entre el evento y la exclusión alegada.

Con fundamento en esta postura, la empresa transportadora sostuvo con vehemencia que entre la exclusión alegada y el siniestro debía existir una relación de causa-efecto porque, de lo contrario, se estaría dejando sin justificación -y sometido al capricho del ente asegurador- la efectividad del contrato de seguro celebrado entre las partes.

\footnotetext{
3 Esta postura fue asumida, a su vez, por el Tribunal Superior de Bogotá en la sentencia proferida el 14 de mayo de 2010, en el proceso 2005-338, con ponencia del Magistrado Ariel Salazar Ramírez. Allí, el Tribunal sostuvo que la diferencia entre las exclusiones y las garantía radicaba en que "(...) mientras las exclusiones deben ser causas reales del evento asegurado, las garantías son causas potenciales enfocadas al momento de celebración del contrato (...)".

${ }^{4}$ C.Co. "Art. 1061.-Se entenderá por garantía la promesa en virtud de la cual el asegurado se obliga a hacer o no determinada cosa, o a cumplir determinada exigencia, o mediante la cual afirma o niega la existencia de determinada situación de hecho.

La garantía deberá constar en la póliza o en los documentos accesorios a ella. Podrá expresarse en cualquier forma que indique la intención inequívoca de otorgarla.

La garantía, sea o no sustancial respecto del riesgo, deberá cumplirse estrictamente. En caso contrario, el contrato será anulable. Cuando la garantía se refiere a un hecho posterior a la celebración del contrato, el asegurador podrá darlo por terminado desde el momento de la infracción.

5 Esta postura también la comparte el tratadista Amadeo Soler Aleu quien sostiene que la prueba de la relación de causalidad sin estral pesa sobre el asegurador que deberá aprobar el extremó en que se exceptúa para liberarse. (Jaramillo, C. 2012. Derecho de Seguros. Editorial. Temis y Pontificia Universidad Javeriana, pp. 217,118)
} 
En otras palabras: si se acepta dicho razonamiento, a la aseguradora le bastaría con demostrar que para el momento en el que ocurrió el siniestro concurrieron todas o algunas de las exclusiones pactadas en el contrato para, con ese único argumento, abstenerse de pagar la indemnización.

Esta postura llevó a la empresa transportadora a sostener tres puntos esenciales: en primer lugar, que la relación de causalidad requerida para que la exclusión prosperara en este caso no existía; en segundo lugar, que la aseguradora no había demostrado la ocurrencia del evento expresamente excluido y, en tercer lugar, que el tenor literal del clausulado de la póliza disponía que el siniestro debía ser causado por el evento expresamente excluido.

En relación con el primer punto, destacó que el Informe Policial de Accidente de Tránsito y el informe pericial fueron concluyentes en que la causa adecuada del accidente de tránsito fue una falla en los frenos del vehículo que no tuvo que ver, de ninguna forma, con el sobrecupo alegado por la aseguradora desde la contestación a la demanda.

En cuanto al segundo punto, sostuvo que la aseguradora no había demostrado con suficiencia la existencia de sobrecupo en el vehículo siniestrado. Y, para respaldar su argumento, indicó que las pruebas practicadas dentro del proceso diferían en el número de lesionados involucrados en el evento.

En relación con el tercer punto, sostuvo que las condiciones generales de la póliza disponían expresamente que se requería un nexo de causalidad entre el siniestro y el evento excluido por varias razones:

- En el aparte introductorio o texto inicial se utilizaba la expresión "como consecuencia de cualquier causa que no se encuentre expresamente excluida";,

- En el encabezado de la cláusula que prevé las exclusiones aplicables a la cobertura de responsabilidad civil extracontractual se utilizaba la frase "generada por"';

- En el encabezado de la cláusula que enlista las exclusiones aplicables a la cobertura de responsabilidad civil contractual se consignaba la frase "generada o proveniente de o que tenga conexión con"».

\footnotetext{
${ }^{6}$ El apartado de la póliza dice, expresamente, lo siguiente: “(...) LA COMPANIÍA, EN CONSIDERACIÓN A LA SOLICITUD DE SEGURO QUE LE HA SIDO PRESENTADA POR EL TOMADOR, INDEMNIZARA HASTA POR LA SUMA ASEGURADA Y CON SUJECIÓN A LOS TÉRMINOS Y CONDICIONES DE ESTA PÓLIZA Y SUS ANEXOS, LAS PÉRDIDAS O DAÑOS MATERIALES QUE SUFRA EL VEHÍCULO DESCRITO EN EL CUADRO, ASÍ COMO LOS PERJUICIOS PATRIMONIALES QUE CAUSE EL ASEGURADO EN RAZÓN DE LA RESPONSABILIDAD CIVIL EN QUE INCURRA DE ACUERDO CON LA LEY, COMO CONSECUENCIA DE CUALQUIER CAUSA QUE NO SE ENCUENTRE EXPRESAMENTE EXCLUIDA Y QUE PROVENGA DE UN ACCIDENTE O HECHO SÚBITO E IMPREVISTO (....)". Énfasis propio

${ }^{7}$ El apartado de la póliza dice, expresamente, lo siguiente: “(...) ESTA SECCIÓN NO CUBRE LA RESPONSABILIDAD CIVIL EXTRACONTRACTUAL GENERADA POR (...)". Énfasis propio

${ }^{8}$ El apartado de la póliza dice, expresamente, lo siguiente: “(...) ESTA SECCIÓN NO CUBRE LA RESPONSABILIDAD CIVIL GENERADA O PROVENIENTE DE O QUE TENGA CONEXIÓN CON (...)". Énfasis propio
} 
Nótese que la postura adoptada por la empresa transportadora no era para nada caprichosa, pues, además de que estaba soportada por la posición de algunos doctrinantes reputados en la materia, para esta era evidente que la aseguradora no podía alegar válidamente la exclusión de sobrecupo por múltiples razones: las pruebas practicadas dentro del proceso apuntaron a que la causa del siniestro fue la falla en los frenos del vehículo automotor (1), el evento de sobrecupo no fue demostrado con suficiencia en los términos previstos en el artículo 1077 del Código de Comercio (2) y, más allá de eso, las condiciones generales de la póliza dispusieron expresamente que se requería un nexo de causalidad entre el siniestro y el evento excluido (3).

Sin embargo, según se verá en el acápite siguiente, la aseguradora controvierte este planteamiento advirtiendo que no existe ninguna norma dentro de nuestro ordenamiento jurídico que exija que las exclusiones deban tener relación causal con el siniestro asegurado.

Al respecto, explica, entre otras cosas, que por ser las exclusiones una descripción negativa de los eventos amparados, no existe ninguna razón por la cual no se pudiesen estipular como eventos no cubiertos algunas circunstancias que harían más gravoso un eventual resarcimiento por parte de la aseguradora -como sería el caso de un sobrecupo para un seguro de responsabilidad civil, en cuyo caso se tendrían que resarcir más víctimas de las inicialmente contempladas en la capacidad de un vehículo-, o que no se pudiesen excluir ciertas consecuencias del riesgo amparado, como si en un seguro de responsabilidad civil se estableciera que no habrá cobertura sobre los perjuicios morales ocasionados a las víctimas.

\section{POSICIÓN DE LA ASEGURADORA}

La aseguradora asumió una postura contraria a la de la empresa transportadora argumentando que las exclusiones no requieren un nexo de causalidad con el siniestro para que sea aplicable la delimitación negativa del riesgo asegurable. Para llegar a esta conclusión, se valió de varios argumentos que analizados en conjunto respaldan la tesis central asumida dentro del proceso: la aseguradora tiene la potestad de delimitar el riesgo a través de límites positivos y negativos de los eventos amparados (2.1.) y, la interpretación de los amparos consagrados en las pólizas de seguro debe ser realizada de manera restrictiva, limitada, consultando la voluntad de las partes plasmada en el texto del contrato $\mathbf{( 2 . 2 )}$.

En este capítulo abordaremos cada uno de los argumentos descritos en el párrafo anterior y, después, expondremos las consideraciones planteadas por la aseguradora para sostener que, en este caso, la exclusión de sobrecupo no requería de un nexo de causalidad con el siniestro para que fuera aplicable la delimitación negativa del riesgo asegurable (2.3).

\subsection{La aseguradora tiene la potestad de delimitar el riesgo a través de límites positivos y negativos de los eventos amparados}

La aseguradora destacó la importancia que tiene la posibilidad de delimitar y calcular los riesgos asumidos haciendo hincapié en que de su habilidad para calcularlos 
actuarialmente, y la posibilidad de delimitarlos adecuadamente, depende el éxito de la actividad aseguradora.

Tal tesis es respaldada por HALPERIN (1972 p. 342), citada en JARAMILlo (2012 p. 3), cuando señaló:

“(...) la posibilidad de limitación de los riesgos es indispensable para el asegurador (...) teniendo presente que sólo se llega a definir cada riesgo y a limitarlo con precisión, si puede medirse y apreciarse su valor para fijar la suma asegurada, la prima y la indemnización o el beneficio: sólo se puede agruparlos en mutualidad y realizar su compensación, si es posible efectuar una clasificación exacta de los riesgos (...)"”.

Ahora, si bien es cierto que algunos autores han considerado que las exclusiones de un contrato de seguro son cláusulas limitativas de la responsabilidad de la aseguradora, otros han explicado, como Abel B. VeIGA $\mathrm{COPO}^{10}$, que ello no resulta acertado porque las exclusiones no son más que una delimitación negativa del riesgo amparado, al señalar los casos en los cuales el asegurado no ha trasladado el riesgo a la aseguradora.

De manera que no podría afirmarse que se está limitando un derecho del asegurado, cuando ni siquiera existe derecho que limitar. Si un evento no está cubierto, por encontrarse por fuera de la delimitación o concreción del objeto del contrato de seguro, no existiría un derecho del asegurado por restringir, pues el asegurado nunca tuvo derecho a gozar de dicha cobertura. Correlativamente, no existiría obligación de la aseguradora por limitar, cuando nunca surgió en cabeza suya una obligación resarcitoria.

Además, la legislación colombiana ha dispuesto, en el artículo 1056 del Código de Comercio, que la delimitación del riesgo asegurado es una potestad de la aseguradora, quien "podrá, a su arbitrio, asumir todos o algunos de los riesgos a que estén expuestos el interés o la cosa asegurados, el patrimonio o la persona del asegurado" ${ }^{11}$.

\footnotetext{
9 Desde el ángulo inmediatamente señalado, como bien lo anota el profesor Abel B. VeIGA Copo, “(...) pueden definirse las cláusulas delimitadoras como aquellas que sirven para definir y concretar el objeto del contrato del seguro de que se trate, de manera que todo acontecimiento o evento acaecido fuera de aquella delimitación, o que constituya una circunstancia de exclusión de cobertura, no tendrá la consideración de siniestro cubierto por la póliza (...)”. (Veiga, A,B. 2005. Condiciones en el contrato de seguro. Ed. Comares, p. 278).

10 Este autor destaca que “(...) las cláusulas de exclusión se sitúan en el ámbito de la delimitación del riesgo, en este caso negativa para el asegurado, y no limitan ningún derecho obtenido, pues el mismo no existe ni existirá, sino todo lo contrario ayudan a que nazcan derechos para el asegurado, puesto que configuran y crean en cierto sentido el riesgo y, una vez que ha nacido, y sólo a partir de ahí y de ese momento, podrán limitarse o cercenarse esos derechos ya obtenidos y nacidos a través de cláusulas ad hoc, esto es, las limitativas de los derechos del asegurado (...)”. (VEIGA, A,B. 2010. Caracteres y elementos del contrato de seguro. Póliza y clausulado. Editorial Biblioteca Jurídica Diké y Universidad Sergio Arboleda, pp. 588 y ss).

11 Particularmente, el profesor Sánchez Calero destaca que en el seguro se “(...) ha de individualizar el riesgo que se quiere asegurar, que depende de la naturaleza del evento que se pretende asegurar y del interés sobre el cual debe verificarse el evento, debiendo producirse en el contrato una delimitación de ese riesgo, con precisión de las causas del evento, el tiempo y el espacio en que debe verificarse (...) las cláusulas establecidas en el contrato no limitan los derechos del asegurado, sino que delimitan el riesgo asumido en el contrato, su contenido, el ámbito al que el mismo se extiende', lo que constituye un límite
} 
Al respecto, la Corte Suprema de Justicia, en la sentencia proferida el 19 de noviembre de 2001, explicó que el asegurador tiene la facultad de asumir a su arbitrio, respetando las restricciones legales, todos o algunos riesgos a los que está expuesto el asegurado $\mathrm{y}$, a su vez, puede limitarlos

“(...) sea circunscribiéndolo por circunstancias de modo tiempo y lugar, que de cumplirse impiden que se configure el siniestro; ora precisando ciertas circunstancias causales o ciertos efectos que, suponiendo realizado el hecho delimitado como amparo, quedan sin embargo excluidos de la protección que se promete por el contrato (...)"'l2.

\subsection{La interpretación de los amparos consagrados en las pólizas de seguro debe ser realizada de manera restrictiva, limitada, consultando la voluntad de las partes plasmada en el texto del contrato}

De la mano del argumento que se expuso en líneas anteriores, la aseguradora sostuvo que los amparos consagrados en las pólizas de seguros deben ser interpretados de forma restrictiva y limitada, consultando la voluntad de las partes plasmada en el texto del contrato de seguro, porque, de lo contrario, se produciría un grave desequilibrio en el conjunto de las operaciones de la aseguradora (Rubén StigLiTz, 2004, pp. 57-71).

Justamente, la naturaleza del contrato de seguro -pero, sobre todo, la importancia de los conflictos en juego-, ha llevado a que la extensión del riesgo y los beneficios otorgados se deban interpretar literalmente, que las restricciones a la libre actividad del asegurado se deban formular expresamente y que la responsabilidad asumida, como fin del contrato, solo se pueda restringir a través de cláusulas expresas (Isaac HALPERIN, 1972, p. 214).

objetivo nacido de la voluntad pactada de las partes (...)”. (SÁnchez, F. 1999. Ley de Contrato de Seguro. Comentarios a la Ley 50 de 1980, de 8 de octubre y sus modificaciones. Editorial Aranzadi, p. 33).

En igual sentido, el profesor Joaquín GARRIGUes sostiene que “(...) al cerrar el contrato, las partes han de estar, pues, de acuerdo sobre los hechos amenazadores, cuya realización engendrará la acción de resarcimiento frente al asegurador. $Y$ es el tomador del seguro quien ha de describir las circunstancias del riesgo, no el asegurador (de aqui la carga de la exacta declaración previa al contrato). Una vez conocidas las circunstancias que sirvan para individualizar el riesgo, su apreciación o estimación incumbe exclusivamente al asegurador, quien, como resultado de este juicio, podrá determinar el grado de probabilidad del siniestro de ese juicio, podrá determinar el grado de probabilidad del siniestro y decidirá si acepta o no reparar sus consecuencias (...) Pero en cada contrato es inexcusable concretar las circunstancias que permitirán decidir si un determinado hecho dañoso entra dentro del riesgo o riesgos previstos en el contrato. Este principio, llamado "principio individualización del riesgo", no significa, sin embargo, que cada contrato de seguro haya de referirse a un riesgo único ...”. (GARRIGUES, J. 1982. Contrato de Seguro Terrestre. Editorial Aguirre, pp. 144-145).

12 M.P. Jorge Antonio Castillo Rugeles, ref.: 5978. En esta sentencia la Corte Suprema de Justicia reiteró que “(...) del cabal discernimiento del artículo 1056 del Código de Comercio puede inferirse que la cobertura de riesgos estipulados, principio en virtud del cual la aseguradora tan sólo asume aquellos que especificamente se indiquen en la póliza pertinente, es la regla general”. 
Tal posición es respaldada por el Ex Magistrado de la Corte Suprema de Justicia, Carlos Ignacio Jaramillo Jaramillo -que, por lo demás, coincide con la de los autores descritos con anterioridad-, cuando sostuvo que

“(...) si bien es cierto que el seguro, por la importante labor social que desempeña, no puede mantenerse frío e incólume frente a las realidades de la praxis cotidiana (...) también lo es que no puede sacrificarse la certeza y seguridad propia de este contrato, asidero de su estructura técnica y financiera, extralimitándola y ampliándola a confines que no se han previsto. La función social del seguro privado, medular en los tiempos que corren, no se compete con la dilatación, apertura o ensanchamiento de la cobertura (...)"'l3.

Además, no se puede perder de vista la importancia que tiene la regla de la interpretación restrictiva en la hermenéutica del contrato de seguro, por su estructura técnica y económica. Piénsese, por ejemplo, que se permita una interpretación extensiva o amplificada de los amparos. Ello haría, sin duda, que la celebración de este tipo de contratos fuera inviable, técnica y jurídicamente.

Por este motivo, la actividad aseguraticia permite que la aseguradora evalúe cada contingencia para que, con base en ello, pueda determinar actuarialmente cuáles riesgos asume y cuáles no, y a cambio de qué prima. En otras palabras: si el asegurador no sabe con certeza a qué se compromete, tendrá que fijar primas excesivamente onerosas para cubrir todas las contingencias o, simplemente, optar por retirarse del mercado al no poder conocer a ciencia cierta el contenido prestacional al que se está obligando, lo que de paso la lleva a no poder hacer una previsión técnica y financiera (JARAMILLO, 2012, p. 43)

\subsection{Las exclusiones no requieren un nexo de causalidad con el siniestro para que sea aplicable la delimitación negativa del riesgo asegurable}

Con fundamento en los argumentos descritos previamente (2.2. y 2.1.), y el contenido literal de las cláusulas pactadas por las partes en el contrato de seguro celebrado, la aseguradora concluyó que las exclusiones no requieren un nexo de causalidad con el siniestro para que sea aplicable la delimitación negativa del riesgo asegurable. Para llegar a esa conclusión, expuso, por un lado, varios argumentos de índole teóricoconceptual (2.3.1.) y, por otro lado, algunas razones relacionadas directamente con el contenido de las cláusulas del contrato de seguro objeto del litigio (2.3.2.). Veamos:

2.3.1. En primer lugar, explicó que si bien es cierto que el sector mayoritario de la doctrina señala que sólo pueden proponerse como exclusiones aquellas que hayan sido la causa del siniestro presentado, no existe en el ordenamiento jurídico colombiano una sola disposición normativa que permita realizar dicha exigencia.

\footnotetext{
13 Laudo Arbitral proferido el 15 de diciembre de 2009 por la Cámara de Comercio de Bogotá para dirimir las controversias surgidas entre Quala S.A. y Chubb de Colombia Compañía de Seguros S.A.
} 
Por el contrario, por ser las exclusiones una descripción negativa de los eventos amparados, no existe ninguna razón por la cual no se pudiesen estipular como eventos no cubiertos algunas circunstancias que harían más gravoso un eventual resarcimiento por parte de la aseguradora -como sería el caso de un sobrecupo para un seguro de responsabilidad civil, en cuyo caso se tendrían que resarcir más víctimas de las inicialmente contempladas en la capacidad de un vehículo-, o que no se pudiesen excluir ciertas consecuencias del riesgo amparado, como si en un seguro de responsabilidad civil se estableciera que no habrá cobertura sobre los perjuicios morales ocasionados a las víctimas. Lo anterior, pues con fundamento en tales variables se realizan los cálculos actuariales para determinar el valor de la prima.

En segundo lugar, concluyó que todo se reduce a un tema de libertad contractual, puesto que el artículo 1056 del Código de Comercio - cuyo alcance fue explicado en líneas anteriores- deja al arbitrio del asegurador la asunción de todos o algunos de los riesgos a los cuales se encuentra sometida la cosa, pudiendo delimitar aquellos riesgos de manera positiva, a través de los amparos, o de manera negativa, a través de las exclusiones.

De ahí que no exista razón alguna para que se le prohíba al asegurador -en su libre arbitrio-no amparar los riesgos a los que está sometido el interés asegurable en ciertas circunstancias, según las variables que se tuvieron en cuenta para el cálculo de la prima. Claro está, que dichas circunstancias deben estar consagradas expresamente en el clausulado de la póliza contratada.

Por lo demás, la aseguradora destacó que es ampliamente conocido en el derecho privado (y en las relaciones existentes entre particulares) que rige el principio de la libertad, permisión o autonomía de la voluntad. De ahí que si no se consagra una norma expresa de carácter imperativo que exija una relación de causalidad entre la exclusión y el riesgo asegurado, esta condición no puede ser exigida por los aplicadores de justicia.

Finalmente, explicó que lo anterior no quiere significar que en los contratos de seguro se pueda pactar cualquier tipo de estipulación sin control alguno, pues es claro que en el derecho de seguros existen múltiples normas imperativas, cuya estipulación en contrario es completamente ineficaz. Sin embargo, las reglas dispuestas en el Título V del libro IV del Código de Comercio son de carácter dispositivo, por lo que las partes, en ejercicio de su autonomía de la voluntad, pueden decidir las condiciones de tiempo, modo y lugar de los riesgos que desean trasladarle a la aseguradora.

2.3.2. Ahora bien, además de las razones teóricas y conceptuales planteadas previamente, la aseguradora complementó su posición a partir de una serie de argumentos relativos al contenido de las cláusulas del contrato de seguro celebrado con la empresa transportadora, de los cuales se desprende que la exclusión de sobrecupo no debe tener relación causal con el siniestro para que sea alegada válidamente por la aseguradora.

Para efectos de que el lector logre un mejor entendimiento de la cláusula objeto de debate, nos permitimos citarla a continuación: 
"LOS AMPAROS DE ESTA POLIZA BAJO NINGUNA DE LAS SECCIONES CUBREN LA RESPONSABILIDAD CIVIL CONTRACTUAL O EXTRACONTRACTUAL:

7.1.1. CUANDO EL VEHÍCULO SE ENCUENTRE CON SOBRECUPO, TANTO DE CARGA COMO DE PASAJEROS O SE EMPLEE PARA USO DISTINTO AL ESTIPULADO EN ESTA PÓLIZA; O SEA ALQUILADO, O CUANDO EL VEHÍCULO ASEGURADO (EXCEPTO GRÚAS Y REMOLCADORES O TRACTOMULAS), REMOLQUE OTRO VEHÍCULO, CON O SIN FUERZA PROPIA” (Énfasis propio)

En primer lugar, la aseguradora argumentó que de una simple lectura del clausulado de la póliza se concluye que esta no cubre la Responsabilidad Civil que sea imputable al asegurado, cuando el vehículo se encuentre con sobrecupo al momento del accidente.

Particularmente, indicó que en ningún momento se exige que el sobrecupo sea la causa eficiente del accidente de tránsito. El riesgo no amparado se consolida con la concurrencia de dicha circunstancia, a saber, que el vehículo se encuentre con sobrecupo al momento del accidente. De manera que esa redacción debe ser respetada por los aplicadores de justicia, según la regla antes explicada de la interpretación restrictiva y literal del texto de la póliza.

En segundo lugar, argumentó que la exclusión mencionada-además de que se trata de una circunstancia que agrava objetivamente el riesgo de ocurrencia del siniestro, pues disminuye la visibilidad del conductor, le genera distracciones adicionales, aumenta el peso del vehículo haciéndolo más propenso a fallas en sus sistemas, y modifica el punto de gravedad del rodante multiplicando las posibilidades de que sufra un volcamiento durante sus giros- le impone el tener que incluir condiciones adicionales (y más gravosas) que aquellas que fueron tenidas en cuenta al momento del cálculo de la prima.

En otras palabras: si al momento de la evaluación y cálculo del monto de la prima la aseguradora toma como base la indemnización máxima a un número de 28 pasajeros, el simple hecho de que tenga que indemnizar muchas más de 36, resulta a todas luces desproporcionado, puesto que le impone cargas adicionales -no contratadas-, que tienen, en general, la posibilidad de hacer inviable al sistema aseguraticio.

Por esta razón, la aseguradora destacó que de manera previa, clara, precisa y expresa estableció, de acuerdo con la potestad establecida en el artículo 1056 del Código de Comercio, que no estaba dispuesta a asumir el riesgo de responsabilidad contractual o extracontractual de los vehículos afiliados a la empresa transportadora, en aquellos casos en los que el vehículo asegurado se encontrara en sobrecupo de pasajeros (para el transporte de pasajeros) o de carga (para el transporte de mercancías). Así quedó plenamente establecido en el texto del contrato de seguro celebrado entre las partes, al inicio de las condiciones generales de la póliza, y redactado en mayúscula y negrilla.

En tercer lugar, argumentó en contra de lo manifestado por la empresa transportadora al sostener que el tenor literal del clausulado de la póliza no indica que el sobrecupo debe ser la causa del siniestro para que opere la exclusión, así como tampoco se puede concluir, de las demás estipulaciones de la póliza, que se exige una relación de causalidad entre todas las exclusiones y el siniestro. 
De manera que la palabra "causados", resaltada reiteradamente por la empresa transportadora para alegar que se requiere un nexo de causalidad entre el siniestro y el evento excluído, no se refiere a que los daños sean causados por el sobrecupo. Simplemente que los daños causados al vehículo o terceros, cuando haya sobrecupo, no están cubiertos. ${ }^{14}$ De ahí que la empresa transportadora no se puede detener únicamente en la palabra "causados", sino que debe demostrar que dicha palabra, desde el punto de vista lógico, está relacionada con el sobrecupo.

Finalmente concluyó que el hecho de que en algunas secciones del clausulado general, relativas a las exclusiones de los amparos de responsabilidad civil contractual y extracontractual, se utilicen frases como "generada por" 15 y "generada o proveniente de o que tenga conexión con", ${ }^{16}$ no significa que todas las exclusiones consignadas tengan que ser la causa del siniestro. El análisis de si dicha relación de causalidad se exige o no, debe realizarse cláusula por cláusula, de acuerdo con lo que las partes hayan estipulado al respecto.

\section{POSICIÓN DE LA CORTE SUPREMA DE JUSTICIA Y COMENTARIOS}

La Corte Suprema de Justicia conoció del recurso extraordinario de casación que interpuso la empresa transportadora en contra de la sentencia de segunda instancia proferida por el Tribunal Superior del Distrito Judicial de Bogotá.

La sentencia de casación se profirió el pasado 23 de noviembre del año $2020^{17} \mathrm{y}$, en ella, la Corte asumió una posición novedosa -apartándose de lo dicho en providencias anteriores y, sobre todo, de lo que han propuesto algunos doctrinantes reconocidos en la materia, como el tratadista J. Efrén OssA G.- al reconocer que en ciertos casos el asegurador puede alegar, válidamente, exclusiones que no tengan relación causal con el siniestro.

En las próximas líneas, expondremos el razonamiento que hizo la Corte a partir de dos grandes grupos de argumentos: la interpretación del contrato de seguro pactado entre

\footnotetext{
${ }^{14}$ Recuérdese que la exclusión dice, expresamente, lo siguiente: "LOS AMPAROS DE ESTA POLIZA BAJO NINGUNA DE LAS SECCIONES CUBREN LA RESPONSABILIDAD CIVIL CONTRACTUAL O EXTRACONTRACTUAL:

7.1.1. CUANDO EL VEHÍCULO SE ENCUENTRE CON SOBRECUPO, TANTO DE CARGA COMO DE PASAJEROS O SE EMPLEE PARA USO DISTINTO AL ESTIPULADO EN ESTA PÓLIZA; O SEA ALQUILADO, O CUANDO EL VEHÍCULO ASEGURADO (EXCEPTO GRÚAS Y REMOLCADORES O TRACTOMULAS), REMOLQUE OTRO VEHÍCULO, CON O SIN FUERZA PROPIA. " Énfasis propio

15 El apartado de la póliza referido por el apoderado de la empresa transportadora dice, expresamente, lo siguiente: “(...) ESTA SECCIÓN NO CUBRE LA RESPONSABILIDAD CIVIL EXTRACONTRACTUAL GENERADA POR (...)". Énfasis propio

${ }^{16} \mathrm{El}$ apartado de la póliza referido por el apoderado de la empresa transportadora dice, expresamente, lo siguiente: “(...) ESTA SECCIÓN NO CUBRE LA RESPONSABILIDAD CIVIL GENERADA O PROVENIENTE DE O QUE TENGA CONEXIÓN CON (...)”. Énfasis propio

17 M.P. Francisco Ternera Barrios, ref: SC4527-2020.
} 
las partes (3.1.) y, la validez de la exclusión del sobrecupo en este caso (3.2.). En el desarrollo de estos puntos se plasmarán unos breves comentarios nuestros al respecto.

\subsection{Interpretación del contrato de seguro celebrado entre las partes}

El eje central de las consideraciones que hizo la Corte Suprema de Justicia en la sentencia de casación partió de las facultades consagradas en los artículos 1056 y 1120 del Código de Comercio que le permiten al asegurador, con las restricciones legales, escoger los riesgos que a su arbitrio quiere amparar y, del mismo modo, excluir aquellos eventos o riesgos inherentes a dicha actividad (p. 34) ${ }^{18}$.

En efecto, explicó que el mecanismo de transferencia del riesgo en un contrato de seguro no es ilimitado “(...) siempre hay alli límites cuantitativos y cualitativos, además de límites impuestos por el legislador. Todo ello sustentado en bases de indole técnica, (...), además de restricciones naturales, como la certidumbre y la imposibilidad que no componen el riesgo" (p. 37).

En otras palabras: esos acontecimientos que asume la aseguradora, que por azar pueden acaecer y generar una necesidad económica en el titular del interés asegurable, necesitan ser precisados. Nadie se imagina que no existan límites temporales, o que el asegurador decida asumir cualquier evento azaroso o sin límites cuantitativos (p. 37).

Por lo tanto, la Corte insistió en que el asegurador debe tener presente, en la delimitación del riesgo, aspectos técnicos que, analizados y aplicados al ramo, la guíen para determinar la tarifa que le debe cobrar al tomador de la póliza, advirtiendo que no hacerlo “(...) conllevaría a un remedo de amparo sin traslación efectiva de riesgos, sucesos que originan pérdidas y, en suma, desembolsos económicos” (p. 35).

En la misma línea, advirtió que estas reglas están dirigidas a morigerar los efectos del carácter aleatorio del contrato de seguro, de modo que el impacto en la transferencia de los riesgos que la aseguradora decida asumir puede ser medido, previamente, en aspectos relacionados con la frecuencia y severidad, de suerte que la prima a proponer sea comercialmente accesible, por un lado, y que, además, sea sostenible económicamente en el tiempo para asumir en el futuro el pago de siniestros al asegurado que los trasladó, por otro lado (p. 33).

Nótese que este razonamiento de la Corte -además de que coincide con la postura adoptada por la aseguradora- demuestra que el análisis de la delimitación del riesgo asegurado es un aspecto que va más allá de una simple formalidad, para convertirse en un estudio técnico en el que se deben analizar las circunstancias que podrían hacer más gravoso un eventual resarcimiento por parte de la aseguradora-como ocurre en el

\footnotetext{
18 En este punto, la Corte trajo a colación lo dicho en la sentencia SC218-2001, proferida el 19 de noviembre de 2001, en el proceso con radicado 5978: “ (...)tratándose del seguro de transporte prevalece el principio de la universalidad de los riesgos que consiste en que la póliza ampara todos los riesgos inherentes al transporte, salvo aquellas excepciones previstas en la ley o que convencionalmente pacten las partes, pues no otra cosa puede deducirse de lo mandado por el artículo 1120 ejusdem”.
} 
caso del sobrecupo, por ejemplo- para evitar un desequilibrio económico injustificado entre el riesgo asegurado y la prima.

De ahí que resulte coherente que, en ejercicio de esa libertad contractual prevista en el artículo 1056 del Código de Comercio, no existan razones para que se le prohíba al asegurador no amparar los riesgos a los que está sometido el interés asegurable en ciertas circunstancias, cuando ellas no fueron tenidas en cuenta para el cálculo de la prima. Claro está, que dichas circunstancias tienen que estar consagradas expresamente en el clausulado de la póliza contratada para poder ser alegadas.

Esta forma de razonar llevó a la Corte a sostener que, en lo que respecta a las exclusiones, estas

“(...)pueden atender a otros razonamientos, válidos siempre que el acotamiento del riesgo tenga una justificación técnica y no obedezcan al capricho del asegurador. $Y$, en esa medida, el asegurador puede excluir de cobertura riesgos materializados en pérdidas al asegurado que tengan relación con un hecho, conducta, situación o evento, aunque estas no sean la causa de la pérdida" (p. 38).

Ahora, de la mano de este argumento, la Corte trajo a colación la postura que asumió en la sentencia proferida el 29 de enero de 1998 cuando sostuvo que la interpretación del contrato de seguro debe hacerse de manera restrictiva y limitada, comprobando la voluntad objetiva consagrada en la respectiva póliza y los documentos que la acompañan con arreglo a la ley (artículos 1048 a 1050 del Código de Comercio), los intereses de la comunidad de asegurados y las exigencias técnicas de la industria ${ }^{19}$.

Y esto no es un asunto menor, pues las exigencias técnicas de la industria y las demás circunstancias que pueden agravar objetivamente el riesgo asegurado son las que, generalmente, se presentan en los siniestros (sobre todo en aquellos involucrados con vehículos, como en este caso). Por lo tanto, es un gran avance que la Corte reconozca que, en aras de garantizar un equilibrio en la actividad aseguradora, el asegurador puede excluir de cobertura los riesgos a los que está sometido el interés asegurable en ciertas circunstancias, cuando estas no fueron tenidas en cuenta para el cálculo de la prima. Pero, por supuesto, tal circunstancia debe acreditarse.

\subsection{Validez de la exclusión del sobrecupo en este caso}

Sobre la validez de la exclusión del sobrecupo en el caso objeto de estudio, la Corte hizo un análisis del clausulado de la póliza de seguro, en contraste con las pruebas practicadas en el proceso y el razonamiento que hizo el Tribunal Superior de Distrito Judicial de Bogotá en la sentencia de segunda instancia.

En relación con el contrato de seguro celebrado entre las partes, indicó que aunque el encabezado de la póliza ${ }^{20}$ era confuso porque incluía la expresión "causados” (y ello podía significar que las exclusiones eran causales), el Tribunal no se quedó allí y

\footnotetext{
19 M.P. Carlos Esteban Jaramillo Schloss, ref: 4894.

${ }_{20}$ Particularmente los amparos de responsabilidad civil contractual y extracontractual.
} 
abordó la otra posibilidad: la causa del accidente fue la falla en el sistema de frenos del vehículo por el mayor peso que recibió como consecuencia del sobrecupo de pasajeros.

Sobre esta última conclusión, la Corte indicó que no era para nada absurda o carente de sentido. Al respecto, expresó que la atribución de responsabilidad comportaba un juicio que englobaba la relación causal -como antecedente fenomenológico dado por la rotura del sistema de frenos-y la imputación jurídica que, bajo la modalidad de causalidad adecuada, tomaba como eficiente la incidencia del sobrecupo en la producción del resultado.

Particularmente, se refirió a las disposiciones del Manual de Infracciones de Tránsito, adoptado a través de la Resolución 003027 del 26 de julio de 2010, para sostener que el sobrecupo de un vehículo exige mayor distancia de frenada y de parada (y, de paso, disminuye la seguridad pasiva y activa del vehículo).

Finalmente, la Corte concluyó que la exclusión del sobrecupo podía ser alegada válidamente por la aseguradora por dos razones: de un lado, porque tenía una justificación técnica (al incrementar la siniestralidad también aumentaba la tarifa), y, del otro, porque jurídicamente no solo implicaba una violación de los reglamentos, sino, peor aún, una culpa grave que si bien en seguros de responsabilidad civil podía entenderse amparada, también era susceptible de ser excluida en forma general o para ciertas conductas (p. 46) ${ }^{21}$.

De este modo, resulta interesante cómo la Corte se apartó de lo que ha dicho en providencias anteriores $^{22}$ (lo cual es coincidente con la posición que han adoptado algunos autores como J. Efrén Ossa G), y adoptó un criterio novedoso al considerar que, por las amplias facultades que tiene la aseguradora para delimitar el riesgo (artículo 1056 del Código de Comercio), basta con que la exclusión tenga una explicación técnica -así no sea la causa adecuada del siniestro- para prosperar, siempre que tenga relación técnica con los hechos o circunstancias que antecedieron la ocurrencia del siniestro acaecido.

Ahora, extendiendo un poco más el análisis, si se pone en contraste el criterio adoptado por la Corte con lo previsto en el artículo 42 de la Ley 1480 de 2011 (o Estatuto del Consumidor $)^{23}$, se puede observar que la exclusión prevista en el contrato de seguro celebrado con la empresa transportadora no resultaba abusiva.

\footnotetext{
${ }^{21}$ En este punto, la Corte indicó que a partir de la Ley 45 de 1990 se entiende asegurada la culpa grave en la responsabilidad civil salvo que medie pacto expreso.

22 Por ejemplo, en la sentencia proferida el 14 de mayo de 2010, en el proceso 2005-338, con ponencia del Magistrado Ariel Salazar Ramírez, el Tribunal Superior de Bogotá sostuvo que la diferencia entre las exclusiones y las garantía radicaba en que “(...) mientras las exclusiones deben ser causas reales del evento asegurado, las garantías son causas potenciales enfocadas al momento de celebración del contrato (...)”. ${ }^{23}$ El artículo 42 de la Ley 1480 de 2011 dispone lo siguiente: "Son cláusulas abusivas aquellas que producen un desequilibrio injustificado en perjuicio del consumidor y las que, en las mismas condiciones, afecten el tiempo, modo o lugar en que el consumidor puede ejercer sus derechos. Para establecer la naturaleza y magnitud del desequilibrio, serán relevantes todas las condiciones particulares de la transacción particular que se analiza (...)”.
} 
Recordemos que una cláusula abusiva, en los términos del artículo mencionado, es aquella que establece un desequilibrio injustificado en perjuicio del consumidor. De manera que cuando autores como J. Efrén Ossa y Carlos Ignacio JARAMILlo sostienen que las exclusiones deben tener una relación causal con el siniestro para ser válidamente alegadas por la aseguradora, imponen exigencias que, incluso, van más allá de lo que prevé la misma Ley 1480 de 2011.

Y la razón de ser es la siguiente: mientras el Estatuto del Consumidor dispone que la cláusula es abusiva cuando establece un desequilibrio injustificado en perjuicio del consumidor (lo que significa, utilizando el argumento a la inversa, que si no hay un desequilibrio o pese a existir el mismo es justificado, la cláusula es válida), en este caso existen múltiples razones distintas al nexo de causalidad entre el siniestro y el evento excluido que ameritan que no haya un desequilibrio o, si lo hay, que el mismo no sea injustificado.

A nuestro juicio, el sobrecupo no supone un desequilibrio porque este es el que, justamente, rompe el equilibrio contractual al agravar objetivamente el riesgo de ocurrencia del siniestro (al disminuir la visibilidad del conductor, generar distracciones adicionales, aumentar por encima de su capacidad el peso del vehículo haciéndolo más propenso a fallas en sus sistemas, y modificando el punto de gravedad del rodante multiplicando las posibilidades de que sufriera un volcamiento durante sus giros), así como haciendo más cuantiosa la ocurrencia de un eventual siniestro (al tener que indemnizar un número mayor de víctimas). Ello impone a la aseguradora condiciones adicionales (y más gravosas) que aquellas que fueron tenidas en cuenta al momento del cálculo de la prima y, por tal motivo, su exclusión es justificada y proporcionada.

Ahora, en gracia de discusión, suponiendo que la cláusula constituía un desequilibrio, este se justificaba perfectamente porque, como dijo la Corte al respecto, el sobrecupo constituye la violación de las disposiciones consagradas en el Código Nacional de Tránsito Terrestre, y puede ser catalogado como un riesgo inasegurable, al haber incurrido el asegurado en culpa grave (artículo 1055 del Código de Comercio), o ser válidamente limitado en un seguro de responsabilidad civil (artículo 1127 del Código de Comercio).

\section{CONCLUSIONES}

A partir de lo dicho por la Corte Suprema de Justicia en la sentencia estudiada, concluimos que no siempre las exclusiones legales o convencionales deben aplicarse con un criterio causal para ser invocadas como eximentes de responsabilidad del asegurador.

En efecto, aunque por muchos años esta Corporación sostuvo lo contrario (amparándose, por ejemplo, en la postura asumida por J. Efrén OssA GómEZ y Carlos Ignacio JARAMILLO), lo cierto es que a partir del razonamiento que hizo en la sentencia recién estudiada, se puede observar que amplía el análisis de la delimitación del riesgo asegurado al considerar las exigencias técnicas de la industria -y las demás circunstancias que pueden agravar objetivamente el riesgo asegurado-, para permitirle 
a la aseguradora excluir de cobertura los riesgos a los que está sometido el interés asegurable en ciertas circunstancias explicables técnicamente, aun cuando estas no son la causa del siniestro acaecido.

Ahora, no es que la sentencia esté abriendo la puerta para que se pueda invocar cualquier exclusión pactada en el contrato de seguro (como si fuera una garantía) para que, sea cual sea la causa, el siniestro no se encuentre cubierto. Lo novedoso de la posición adoptada por la Corte es que no tiene que existir una relación de causalidad entre la exclusión y el siniestro acaecido para que la misma pueda ser válidamente alegada, sino que basta con que esta tenga una justificación técnica que sea razonable, por un lado, y que esté relacionada con los hechos o condiciones que antecedieron la ocurrencia del siniestro acaecido (como en este caso que el sobrecupo incrementaba la siniestralidad y la tarifa), por el otro.

Por último, concluimos que la cláusula contentiva de la exclusión no era para nada abusiva. Como se indicó previamente, a nuestro juicio el sobrecupo no supone un desequilibrio. Todo lo contrario: es el asegurado quien, justamente, rompe el equilibrio contractual al agravar objetivamente el riesgo de ocurrencia del siniestro (al disminuir la visibilidad del conductor, generar distracciones adicionales, aumentar por encima de su capacidad el peso del vehículo haciéndolo más propenso a fallas en sus sistemas, y modificando el punto de gravedad del rodante multiplicando las posibilidades de que sufriera un volcamiento durante sus giros), así como hace más cuantiosa la ocurrencia de un eventual siniestro (al tener que indemnizar un número mayor de víctimas). Establecer una cláusula que excluya los siniestros acaecidos en tales circunstancias, que rompen objetivamente el equilibrio económico y actuarial existente entre riesgo y prima, es apenas justificado y proporcional.

Finalmente, en gracia de discusión, suponiendo que la cláusula constituía un desequilibrio, este se justificaba perfectamente porque, como dijo la Corte al respecto, el sobrecupo constituye la violación de las disposiciones consagradas en el Código Nacional de Tránsito Terrestre, y puede ser incluso catalogado como un riesgo inasegurable, al ser una conducta configurativa de culpa grave (artículo 1055 del Código de Comercio), o válidamente limitada en un seguro de responsabilidad civil (artículo 1127 del Código de Comercio).

\section{BIBLIOGRAFÍA}

\section{A. Doctrina}

Garrigues, J. (1982). Contrato de Seguro Terrestre. Editorial Aguirre.

HalPerin, I. (1972). Seguros. Exposición crítica de la Ley 17.418. Editorial Depalma.

Jaramilllo, C,I. (2012). Derecho de Seguros. Editorial Temis y Pontificia Universidad Javeriana.

Josserand, L. (1951). Derecho civil. Tomo II. Vol. II. Contratos. Ediciones Bosch.

Ossa, J, E. (1991). Teoría general del seguro: el contrato. Editorial Temis. 
Sánchez, F. (1999). Ley de Contrato de Seguro. Comentarios a la Ley 50 de 1980, de 8 de octubre y sus modificaciones. Editorial Aranzadi.

Stiglitz, R. (2004). Derecho de Seguros. Editorial. La Ley.

Stiglitz, R. (2008). Derecho de Seguros, Tomo I, 3ra Edición actualizada y ampliada. Editorial La Ley.

Veiga, A,B. (2010). Caracteres y elementos del contrato de seguro. Póliza y clausulado. Editorial. Biblioteca Jurídica Diké y Universidad Sergio Arboleda.

Veiga, A,B. (2005). Condiciones en el contrato de seguro. Editorial. Comares.

\section{B. Jurisprudencia}

Corte Suprema de Justicia, Sala Civil, 23 de noviembre de 2020, RAD: 11001-31-03-019-201100361-01 MP Francisco Ternera Barrios.

Corte Suprema de Justicia, Sala Civil, 19 de noviembre de 2001, REF: 5978, MP Jorge Antonio Castillo Rugeles.

Corte Suprema de Justicia, Sala Civil, 26 de enero de 1998, REF: 4894, MP Carlos Esteban Jaramillo Schloss.

Corte Suprema de Justicia, Sala Civil, 4 de abril de 1997, GACETA JUDICIAL: CXVII

Corte Suprema de Justicia. Sala Civil, 7 de octubre de 1985, GACETA JUDICIAL: CLVIII

Corte Suprema de Justicia. Sala Civil y Agraria. 13 de mayo de 2008. RAD: 11001-3103-0061997-09327-01, MP César Julio Valencia Copete.

Corte Suprema de Justicia. Sala Civil. 21 de junio de 2012. RAD: 0500122030002012-0039201, MP Fernando Giraldo Gutiérrez.

Tribunal Superior de Bogotá, Sala Civil y Agraria, 14 de mayo de 2010, RAD: 2005-338, MP Ariel Salazar Ramírez.

Tribunal Supremo de España, Sala Civil, 18 de septiembre de 1999. RAD: 6940/1999, Revista de Derecho Mercantil de Madrid.

\section{Laudos arbitrales}

Laudo “Quala S.A. v. Chubb de Colombia Compañía de Seguros S.A.” del 15 de diciembre de 2009.

\section{Códigos}

Código de Comercio (1971). Legis.

\section{E. Leyes}

Ley 769 de 2002.

Ley 1480 de 2011. 


\section{F. Resoluciones}

Resolución 003027 del 26 de julio de 2010.

\section{G. Conceptos}

Ministerio de Transporte en concepto MT-1350-2 - 23801 del 29 de abril de 2008. 
